\title{
Some doctors barred from retaking licensing
}

\section{exams}

Cite as: CMAJ 2020 July 20;192:E849-50. doi: 10.1503/cmaj.1095883

Posted on cmajnews.com on July 3, 2020

$\mathbf{T}$ he College of Family Physicians of Canada will prohibit some doctors from retaking licensing exams for family medicine and a certificate of added competence in emergency medicine this year due to the pandemic.

Both exams have oral components, which the College is waiving this year for doctors sitting the tests for the first time. But doctors who have previously failed either the written or oral component of the emergency medicine certification, or the oral component of the family medicine exam, must wait until 2021 to retake the tests.

Some of these doctors may continue practising under provisional licences with supervision or in hospitals that don't require a certificate of added competence in emergency medicine. But those negatively affected by the delay argue that it's unfair for the College to hold back one group of candidates for oral testing while licensing others based on written exams alone.

Dr. Catherine Wong, who practises rural family medicine in British Columbia and northern Ontario, says the decision discriminates against candidates who are "already disadvantaged" heading into the exams.

Many of the doctors who retake the tests are international medical graduates and those, like Wong, who decided to specialize in emergency medicine later in their careers. They often lack the benefit of the study sessions, mentors and other support available to help resident doctors prepare for the exams.

Wong had hoped to complete her emergency medicine certification this fall before starting a family, but now she faces the prospect of studying for next year's exam while caring for a newborn. Without full certification, she can't take on additional leadership and teaching positions. Others in Wong's situation have had to give up jobs because they won't get the certification in time - many, but not all, emergency departments require it. "The stories are heartbreaking," she says.

Wong has launched a petition calling on the College to either allow all candidates to write the 2020 exam without an oral component or offer an oral test virtually.

According to Dr. Brent Kvern, director of certification and examinations at the College, the board overseeing the exams considered "every possible scenario, from nobody writing to everybody writing."
Kvern says the College decided not to conduct in-person oral exams in the fall because it wouldn't be responsible to gather examiners, candidates, administrators and volunteers from across Canada during a pandemic. They also deemed that switching to a virtual oral exam by the fall wouldn't be feasible. "How do we securely distribute all the information? How do we ensure the examinee doesn't unfairly benefit from other technologies and people in the room? How do we handle technical glitches?"

The College would have preferred to suspend the exams entirely but worried that keeping around 2000 post-residency doctors from fully entering practice would

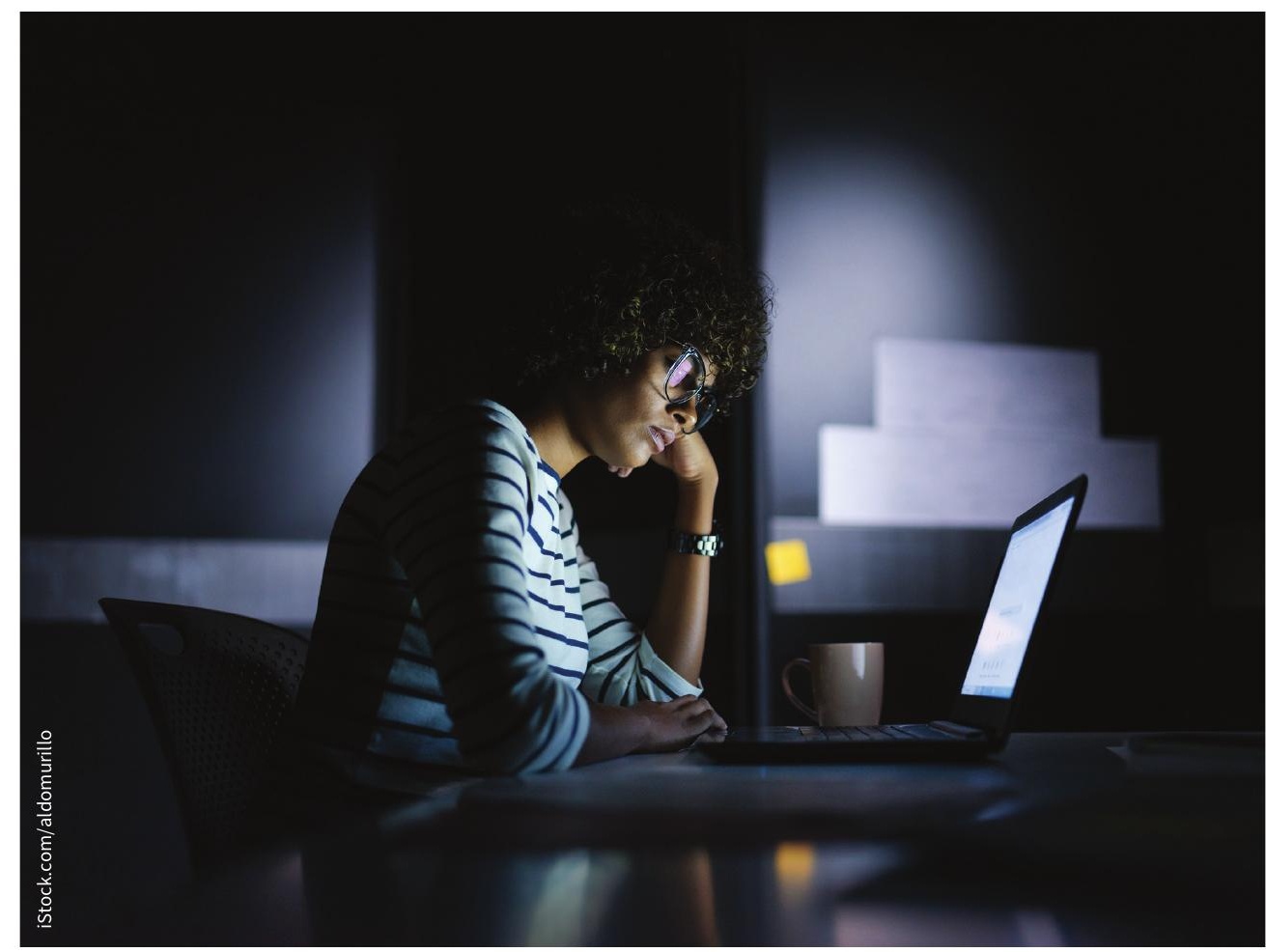

Only some doctors will be able to sit licensing exams for family medicine and a certificate in emergency medicine this year. 
contribute to workforce shortages. What's more, "we know from data that first-timeever takers of the examination have a very high pass rate," Kvern says.

By contrast, the approximately 130 repeat candidates excluded from the 2020 exams "have already demonstrated they didn't meet our standard," he says. "We felt that if you had failed one of the components before, you needed to do that component again."

Not all repeat candidates failed the exams the first time around. In at least one case, a woman who couldn't take the family medicine oral exam in 2019 due to pregnancy complications will have to wait until oral exams resume in 2021.

According to Kvern, the College is applying the repeat candidate rule "fairly" based on the year a candidate registered for the exam, regardless of individual circumstances.

However, many repeat candidates take issue with the notion that they are second-class candidates when they are already working at the front lines of their desired specialties.

Dr. Alhussein Alfaour has studied an hour a day in preparation to retake the emergency medicine certification after failing "by a small margin, $0.1 \%$," last year. Until he can take the test again, Alfaour splits his time between Saskatoon, where his wife works, and a town more than two hours away, where he works in a hospital that doesn't require the College's emergency medicine certification.

"There are many, many other ways to deal with this crisis, rather than just cancel for one group of people without even asking us about the options," says Alfaour. He doesn't want to "get out" of taking the oral exam - he wants the chance to complete it.

Another doctor who wanted to remain anonymous says that his provisional licence prevents him from working on weekends and holidays, putting extra burden on his colleagues. "I feel like I'm not carrying my weight, and every time the call schedule is reviewed, I have to remind them of my 'situation.' It's humiliating and I wonder when they'll run out of patience," he says.

Dr. Sarah Giles, an emergency physician in northern Ontario, supports Wong's petition and worries about the toll further delay will take on repeat candidates.

"People are devastated when they fail the exam. They need their chance to prove themselves, to become full-fledged family physicians and emergency physicians, and to move on. This is harmful to the mental health of these folks," she says. "I can't imagine having studied for these exams for months and having the chance yanked away."

According to Kvern, the College spent hours weighing the decision to delay exams for repeat candidates. "It was not taken lightly," he says.

Wendy Glauser, Toronto, Ont. 